\title{
Arquivos Pessoais, História Oral, Blogs e Rock Alternativo
}

"Personal Archives, Oral History, Blogs and Alternative Rock"

Ricardo Neumann ${ }^{1}$

ricardoneumann@hotmail.com

Resumo

Em minha tese de doutorado estudo a cena musical alternativa norte catarinense nas décadas de 19902000. Para um estudo das bandas, dos integrantes, dos espaços de sociabilidade da cena, faço uso em meu trabalho dos arquivos pessoais de muitos dos participantes da mesma. São cartazes, fotos, vídeos, gravações de fitas demo, fanzines, entre outros materiais, que fazem parte da história da cena. Neste artigo, faço uso da História Oral na interpretação dos arquivos pessoais. E, através da pesquisa nestes arquivos pessoais, busco explicitar um pouco do objeto de minha pesquisa, a cena musical alternativa norte catarinense nas décadas de 1990-2000.

Palavras chave: Cena Alternativa Norte Catarinense, História Oral, Arquivos Pessoais

\begin{abstract}
In my doctoral thesis I study the alternative music scene in the north of Santa Catarina in the 1990's and 2000's. For a study of the bands, the participants, the spaces of sociability in the scene, I use in my work the personal archives of many of the participants in such scene, such as posters, photos, videos, demo tapes, fanzines, and other materials which are part of this scene. In this article I use Oral History to interpret the personal archives. And, through research of these personal archives, I seek to explain a little about the object of my research, the alternative music scene in the north of Santa Catarina in the 1990's and 2000's.
\end{abstract}

Keywords: Alternative Scene in the north of Santa Catarina, Oral History, Personal Archives

Em minha tese de doutorado, estudo "a cena musical alternativa norte catarinense nas décadas de

1 Doutorando em História Cultural pela Universidade Federal de Santa Catarina. 
1990-2000", com suas bandas autorais e independentes, seus espaços de sociabilidade e suas identidades underground. Em cidades como Joinville, Guaramirim, Jaraguá do Sul, Schroeder e Blumenau, jovens criaram diversas bandas autorais independentes e, consequentemente, muitos espaços de sociabilidade, nos quais os mesmos buscavam se expressar criativamente, numa busca sem muita organização por um rompimento com as tradições e as normas sociais vigentes nos anos 1990. As bandas às quais me refiro faziam um som inspirado em diversos estilos. Entre estes estilos podemos elencar: o rock, punk rock, o hardcore, o skacore, o indie rock, o grunge, o metal e suas variantes (de Beatles a Nirvana, entre outros). E apesar da diversidade de estilos, as bandas formavam um único movimento, que tinha como base dessa unidade o fato de que as letras e as músicas eram de autoria das próprias bandas. Nas letras, no estilo musical e nas atitudes de muitos destes jovens podemos observar muito do pensamento de uma juventude que não aceitava passivamente a violência policial, a hipocrisia da religião e da sociedade em geral, com seus preconceitos e tradições.

Para o estudo da história das bandas, dos participantes, dos shows e dos espaços que compunham a cena, irei analisar fontes como: jornais, cartazes, gravações, capas defitas demo, letras de músicas, fotos, vídeos e fanzines (jornais alternativos). Dentre estas fontes, os jornais são encontrados em bibliotecas, na internet e arquivos públicos e em arquivos pessoais; as muitas gravações de fitas, vídeos e fotos estão atualmente disponíveis na internet, mas pertencem a arquivos pessoais. Os fanzines (jornais alternativos), cartazes de shows e capas das fitas demo, que são produções diretamente ligadas ao tema, também estão disponíveis nos arquivos pessoais de muitos dos participantes da cena.

Ao deparar com a questão dos arquivos pessoais em minha pesquisa pude observar que há por parte de muitos pesquisadores uma inquietação, uma dificuldade teórico-metodológica, no trato com os arquivos pessoais. Para autores da ciência da arquivística, como Ana Maria de Almeida Camargo ${ }^{2}$, os arquivos pessoais não poderiam ser analisados por seu caráter autobiográfico, os mesmos apenas deveriam exercer sua função probatória original, que definisse o "modus operandi" de alguém. Enfim, para a arquivística, os arquivos pessoais deveriam ser tratados como qualquer outro arquivo. No entanto, como coloca Luciana Heymann, não é fácil tratar arquivos pessoais com a metodologia da arquivística, pois:

\footnotetext{
"Não nos parece simples, porém, a tarefa de identificar os contextos em que são criados e utilizados todos os documentos passíveis de integrar os arquivos pessoais, já que tais conjuntos documentais se caracterizam por comportarem uma variedade sem limites de tipos de documentos, incluindo os que remetem à vida pessoal, à intimidade, mas também às idiossincrasias e ao cotidiano dos titulares. Isso significa que o conjunto que resulta da acumulação documental realizada por um indivíduo pode conter tanto documentos "identificáveis" do ponto de vista das atividades que os originaram como outros, de mais difícil localização no tempo e no espaço, cujos conteúdos mesmo são imprecisos, escapando a uma abordagem de tipo funcional."3
}

Os arquivos pessoais têm suas especificidades como coloca Heyman. Para a autora, as diferenças entre os arquivos pessoais e os outros arquivos "dizem respeito à tipologia de documentos que abarcam, à informalidade que caracteriza o arquivamento e

às razões para a acumulação, distantes muitas vezes da motivação probatória". ${ }^{4}$ Neste sentido, Heyman critica o método funcional da ciência arquivística no trato para com os arquivos pessoais. Ou seja, se tratando de arquivos pessoais, exceto os de homens públicos, que têm seus arquivos custodiados constantemente, como o fundo $\mathrm{FHC}^{5}$, por exemplo, é difícil respeitar os preceitos da ordem acumuladora e do caráter probatório dos documentos pessoais.

2 CAMArgo, Ana Maria de Almeida. “Arquivos Pessoais são Arquivos”. Revista do Arquivo Público Mineiro, Belo Horizonte, n. 2, PP. 26-39, jul-dez 2009.

3 HEYMANN, Luciana Quillet. O individuo fora do lugar. Revista do Arquivo Público Mineiro, Belo Horizonte, n.2 pp.40-57, jul-dez, 2009, p. 48.

4 Idem, p. 49

5 Fundo este organizado e estudado por Ana Maria de Almeida Camargo. 
Para Letícia $\mathrm{Nedel}^{6}$, cada arquivo pessoal tem uma fisionomia particular. Segundo Nedel, os mesmos estão sujeitos "às idiossincrasias dos produtores com suas diferentes motivações e estratégias de acumulação". Para a autora, eles "resistem a categorizações pontuadas por um princípio funcional de classificação". Em minha tese, observarei os arquivos pessoais seguindo Nedel e Heymann. Neste sentido, buscarei observar os arquivos pessoais como conjuntos complexos, que contêm documentos que são muito mais que um mero reflexo das atividades de seus titulares, que permanecem no que Heymann chama de "zona indeterminada”. Assim, para além do caráter probatório do princípio funcional da arquivística, observarei em minha tese a intencionalidade, o trabalho de memória, de autorreflexão e de autoadestramento ${ }^{7}$ existentes nos arquivos pessoais.

Segundo Heymann, estas “zonas indeterminadas”, que são os arquivos pessoais,

merecem uma investigação em profundidade sobre "os usos e sentidos dados pelos titulares" aos mesmos $^{8}$. Para isto, trabalho neste artigo com uma entrevista cedida a mim em janeiro deste ano (2014) por um participante da cena norte catarinense da década de 1990, mas que ainda está tocando em uma banda atualmente. Seu nome é Edson Luis de Souza, ex-vocalista da banda The Power of the Bira, organizador de muitos shows no Curupira e dono da loja de Lp's e Cd's "Abrigo Nuclear", atualmente baterista da banda “Os Fritz da Puta”, de Jaraguá do Sul. Assim, neste artigo faço o uso da História Oral como uma ferramenta metodológica que me auxilie na compreensão da construção dos arquivos que trabalharei em minha tese. Dessa forma, buscando uma pesquisa mais aprofundada a respeito dos mesmos.

$\mathrm{O}$ arquivo pessoal estudado aqui, no caso o de Edson, é como a grande parte dos arquivos pessoais, peculiar. As razões para o arquivamento, os materiais arquivados, o modo como são arquivados, o fato do arquivo ainda estar sendo montado, tudo se distancia e muito da visão do que seria um arquivo para a tradição da ciência arquivística. Assim, para percebermos as diversas dimensões da constituição dos arquivos pessoais, analisaremos os mesmos por meio de uma perspectiva histórica, como aponta Heymann. ${ }^{?}$

$\mathrm{O}$ arquivo pessoal de Edson vem de sua relação com a música e a cena alternativa do norte catarinense. Nascido em Joinville, mas atualmente morando em Jaraguá do Sul, Edson foi o vocalista de uma das primeiras bandas alternativas de Joinville, o "The Power of the Bira”. Sua participação como músico foi seguida de sua colaboração à cena como organizador, uma espécie de produtor dos shows que aconteciam na cidade de Guaramirim, no Curupira Rock Club. Em seu arquivo pessoal, encontramos vinis, fitas demo, CDs, fanzines (jornais alternativos) e cartazes que contam um pouco da história da cena alternativa dos anos 1990.

A construção de seu arquivo data dos primeiros vinis que ele comprou, das primeiras fitas demo que ele comprou ou ganhou, dos primeiros shows que o mesmo participou. Segundo ele "os cartazes dos shows são guardados desde o primeiro show" ". Inicialmente estes cartazes serviam para avisar ao público dos eventos, mas para Edson o fato dos mesmos serem colagens feitas manualmente, serem "obras de arte" para ele, o fizeram guardá-los. Sua função de organizador de shows no Curupira também o ajudou a acumular estes cartazes, bem como fitas demo e CDs das bandas que lá tocavam.

Segundo Edson, seu lado "arquivista" vem desde sua infância. O mesmo diz que uma das razões para a acumulação de tanto material sobre a cena é o simples fato de "gostar de guardar" 11. Ele conta que na adolescência ganhou um disco de sua irmã, um disco que segundo o mesmo não o agradou muito e por isso ele o vendeu. No entanto, até hoje Edson diz se arrepender de ter se desfeito de um presente. Em 1996, Edson abriu com sua esposa e um amigo a loja de música (vinis,CDs, roupas) "Abrigo Nuclear”, em Jaraguá do Sul. Como ele disse, a loja se mantinha, não que ele ganhasse muito dinheiro, nas palavras do mesmo,

6 NEDEL, Letícia Borges. 'Da Sala de Jantar à Sala de Consultas: o arquivo pessoal de Getulio Vargas nos embates da história política recentes. In: TRAVANCAS, Isabel; ROUCHOU, Joelle; HEYMANN, Luciana. (Org.). Arquivos Pessoais: reflexões multidisciplinares e experiências de pesquisa. 1ed.Rio de Janeiro: Editora FGV/FAPERJ, 2014, v. 1, p. 131-164, p.7.

7 Idem, p.8

8 HEYMANN, Luciana Quillet. O individuo fora do lugar. Revista do Arquivo Público Mineiro, Belo Horizonte, n.2 pp.40-57, jul-dez, 2009.

9 Idem, p. 52

10 Entrevista concedida pelo músico Edson Luis de Sousa, Jaraguá do Sul (SC), ao doutorando Ricardo Neumann, em 28.1.2014.

11 Ibdem 
"não deu para comprar uma bicicleta", mas as contas eram pagas. Entretanto o advento do MP3 no inicio dos anos 2000 fez com que as vendas baixassem demasiadamente, o que resultou na falência da loja. Nesta época, antes de retomar sua antiga profissão de técnico de manutenção, Edson pensou em vender sua coleção de vinis, porém:

\begin{abstract}
“2002, então foi a época que me deu vontade, vou vender esses discos, mas daí aconteceu assim, eu consegui um emprego rápido, bolei um currículo, comecei a mandar e cara coisa assim de cinco dias já me chamaram, comecei a trabalhar rápido também. Só que assim, trabalhar com manutenção foi aquela coisa full time, 24 horas disponível pro trabalho, então eu fiquei tipo assim uns dez anos nesse ritmo, domingo, feriado, de manhã, de madrugada, a noite, a tarde. Então meio que a música voltou a ser hobby, voltou a ser hobby, o que era mais ou menos digamos na minha adolescência. Não precisei me desfazer dos discos, então essa foi a vantagem e tudo que eu consegui comprar depois, paguei todas as dividas, no caso a minha parte que eu tinha que pagar, paguei tudo, não fiquei devendo pra ninguém, trabalhei praticamente um ano só pagando pepino, ganhava o mês, ta aqui, ganhava o mês, ta aqui (...). ${ }^{12}$
\end{abstract}

Como Edson disse, após o fim da loja, a música voltou a ser um hobby para o mesmo. Porém, este hobby começou a dar frutos há mais ou menos cinco anos, época em que nasceu seu filho Daniel. Segundo Edson, após o nascimento de Daniel, as noites de sexta e sábado passaram a ser curtidas em casa. Foi aí que ele iniciou um trabalho de digitalização das fitas $\mathrm{K} 7$ que continham as músicas das bandas alternativas e dos cartazes dos shows antigos. Seu primeiro blog foi o "Joinroll", blog que contém bandas de Joinville, suas gravações digitalizadas e cartazes digitalizados de shows que as mesmas participaram, um breve histórico de cada banda e imagens das capas das demos e fotos das bandas.

Hoje Edson tem cinco blogs. Além do Joinroll, ele mantém um blog de sua antiga banda "The Power of the Bira", com todo o material produzido pela banda entre 1992 e 1996, um blog sobre sua atual banda "Os Fritz da Puta", um blog sobre o Curupira Rock Club, onde ele organizava os shows, que contém os cartazes dos shows do local desde 1992 (primeiro show) até os mais recentes, dispostos por data de realização, e um blog chamado Demo Tapes Brasil, no qual Edson já disponibilizou gravações digitalizadas de mais de 450 fitas demo de bandas de todo o Brasil.

Neste artigo, vou explicitar um pouco da cena musical alternativa norte catarinense por meio dos blogs: Joinroll- Memória do rock de Joinville e região, Demo Tapes Brasil e Histórico-Curupira. Como coloca José Vinci de Moraes $^{13}$, no século XX, os acervos digitais são um importante repositório de fontes, principalmente as audiovisuais. Materiais como demo tapes (fitas cassetes) das bandas a serem estudadas em minha pesquisa se encontram hoje digitalizadas e disponíveis a todos na internet. Além de estes arquivos juntarem materiais de diferentes origens, e que só estão compilados lado a lado graças ao trabalho individual dos administradores e colaboradores dos blogs, eles também garantem que os audiovisuais sejam preservados, já que fitas cassetes e VHS são suportes de fácil deterioração.

Por meio da pesquisa no blog Joinroll, percebemos a dificuldade de se expressar criativamente por músicas autorais nos anos 1980 em Joinville e região. Segundo Edson, em seu blog:

Os anos 80 em Joinville não foram fáceis para quem gostava de rock autoral. Apesar do boom que vivíamos com o rock nacional (vide Barão Vermelho, Titãs, Paralamas, Legião Urbana, Capital Inicial, etc) a cena musical de Joinville era uma lástima. Covers, covers e mais covers... Uma das excessões se chamava Tensão Superficial. Um mistura de Punk, Dark e New Wave com forte proposta a músicas autorais (raríssimo na época). Iniciou as atividades em 1986 durando até 1992. Gravou alguns músicas no estúdio do Mug (Rip) em formato demo, mas oficialmente nunca lançou nada. Sabe lá onde andam essas fitas...Felizmente pude assistir (ainda muito jovem lá por volta de 89) a um show deles na finada boate Baturité e adquirir uma fita paga antecipadamente, com promessa de ser entregue em uma semana que na realidade levou meses para chegar em minhas mãos. Felizmente guardei-a a sete chaves e disponibilizei-a a cerca de 2 anos atrás na internet. O resto é história... A banda voltou para alguns shows (que infelizmente não pude ver) e temos um pedacinho dessa história (boa!) do Rock de Joinville guardada para a eternidade graças a tecnologia dos arquivos em mp3.

12 Ibdem

13 VINCI DE MORAES, José Geraldo. Música en conserva. In: Memoria e Historia de la música en Brasil. VINCI DE MORAES, José Geraldo, MACHADO, Cacá. en BRESCIANO, Juan. La memoria histórica y sus configuraciones temáticas. Una aproximación interdisciplinaria. Montevideo, Ediciones Cruz del Sur, 2011. 
Neste sentido, vemos, por um lado, a importância das novas mídias na preservação dos documentos audiovisuais e, por outro lado, a realidade das bandas autorais em cidades periféricas, fora, principalmente, do eixo Rio-São Paulo. A banda Tensão Superficial é um dos raros exemplos de tentativa de música autoral em Joinville e região nos anos 1980, e como a mesma quase não tinha registros, gravações, para além de uma fita K7, o blog e a digitalização desta fita são de suma importância na manutenção da memória musical da região.

Com condições muito precárias, a maioria das 58 bandas elencadas no blog deixou apenas registros caseiros em fita K7, ou seja, sem qualidade de gravação e de mídia. Assim como em muitas outras cenas independentes brasileiras, na maioria das vezes as bandas contavam apenas com seus próprios recursos, em uma realidade muito distinta de outras cenas ao redor do mundo. Se observarmos as bandas alternativas dos anos 1960-1970, nos Estados Unidos, vemos que bandas totalmente desaprovadas pelo grande público, como Velvet Underground ou Stoogies, eram apoiadas financeiramente por gravadoras e produtores ${ }^{14}$. Já no Brasil, não só nos anos 1980, mas também na década de 1990, as bandas alternativas tiveram dificuldades para expor seus trabalhos autorais.

O trabalho de Edson e outros colaboradores do seu blog ou de outros blogs, como o blog "Música que nos consome", vem nos últimos anos compilando, digitalizando e repassando através da internet as produções das bandas autorais norte catarinenses e de todo o Brasil. Como já vimos, para além do blog Joinroll, os arquivos pessoais dos participantes de várias cenas do Brasil deram origem ao blog Demo Tape Brasil. Para se ter uma ideia da produtividade das bandas autorais independentes da cena alternativa brasileira da década de 1990, na entrevista cedida a mim por Edson, o mesmo disse que para além das 450 fitas que o mesmo já disponibilizou no blog, existem ainda pelo menos mais 450 a serem digitalizadas. São demo-tapes de bandas alternativas de cenas de inúmeras regiões do Brasil. Existem bandas de Santa Catarina, do Rio Gran-

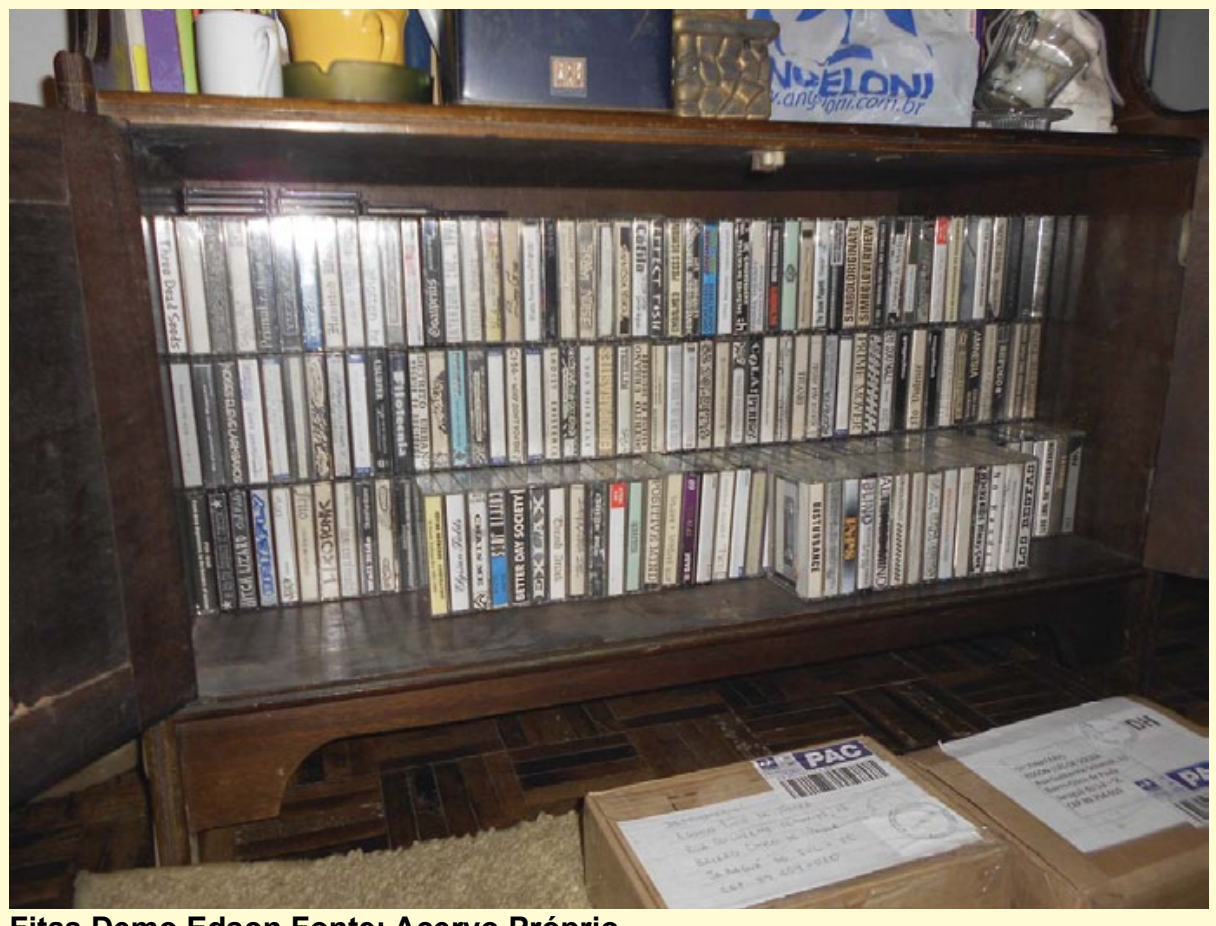

Fitas Demo Edson Fonte: Acervo Próprio de do Sul, do Paraná, de São Paulo, do Rio de Janeiro, Espírito Santo, Minas Gerais, Bahia, Pernambuco, Rio Grande do Norte, Ceará, Goiás, do Amazonas, entre outros. Este grande número de bandas independentes produziram inúmeras músicas próprias, que podem ser vislumbradas nas mais de 900 fitas arquivadas por diversos participantes das cenas e reunidas por Edson e que demonstram quanta produção criativa existiu nos anos 1990 no Brasil e que por sua natureza autoral, independente e alternativa, passou invisível aos olhos da maioria das pessoas que viveram a época ou que estudam música no Brasil.

No blog, Histórico-Curupira, que trata sobre o Curupira Rock Club, que pode ser considerado o maior espaço da música autoral norte catarinense, ou como coloca o colunista do Jornal A Notícia, Rubens Herbst, "uma lendária trincheira da música autoral alternativa, o nosso CBGB’S, símbolo do rock 'n roll catarinense" ${ }^{15}$, podemos observar uma linha do tempo (1992 - 2014) do Curupira Rock Club feita com os cartazes dos shows que foram guardados por Edson e outros participantes da cena.

Como afirmou Edson, sobre os cartazes que o mesmo acumulou, "o fato de os mesmos serem colagens feitas manualmente" o fez com que ele os considerasse "obras de arte". Se pensarmos nas produções dos cartazes, folders de shows e jornais alternativos, os fanzines, da cena norte catarinense e do resto do

14 MCNEIL, Legs \& MCGAIN, Giullian. Mate-me por favor: Uma história sem censura do punk. Porto Alegre - L\&PM, 1997.

15 Ver ESPÍNDOLA, Marcos. Lugar do Caralho. Diário Catarinense, Florianópolis, 19 maio. 2011. Variedades, p. 8. 


\section{Artigos}

Brasil, temos uma gama enorme de produções artísticas originais e que representam um momento pouco estudado, mas muito prolífico da cultura brasileira. As bandas dos anos 1990 das diversas cenas alternativas



\section{Cartazes Edson Fonte: Acervo Próprio}

do Brasil produziram inúmeras músicas, performances e outras artes como os cartazes e as capas das fitas demo, que merecem um olhar mais apurado dos pesquisadores da História da Arte e da Música Brasileira.

Assim, em minha pesquisa irei utilizar os Arquivos Pessoais dos participantes da cena, os Blogs que digitalizaram estes arquivos e a História Oral para melhor compreender os mesmos. Através dos mesmos irei analisar as fontes audiovisuais presentes nestes arquivos e compreender a história de meu objeto de pesquisa, a cena alternativa norte catarinense entre 1992-2002, por meio das músicas, das letras das mesmas, das capas das fitas demo, dos cartazes para os shows, dos fanzines e de todas as outras expressões artísticas criativas elaboradas pelos participantes da cena e felizmente, hoje, disponibilizadas em blogs.

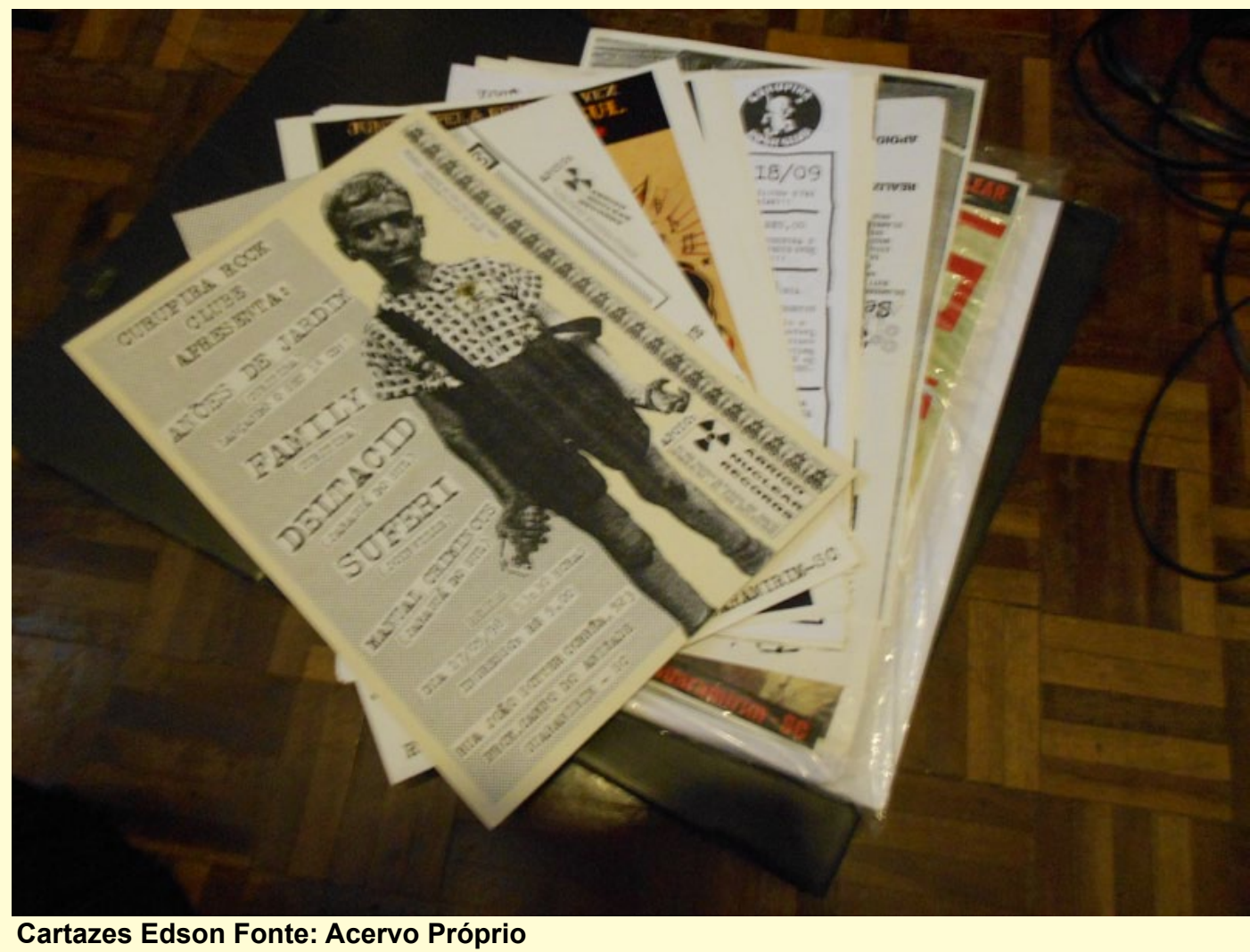




\section{Referências bibliográficas:}

CAMARgO, Ana Maria de Almeida. “Arquivos Pessoais são Arquivos”. Revista do Arquivo Público Mineiro, Belo Horizonte, n. 2, PP. 26-39, jul-dez 2009.

CAMARGO, Ana Maria de Almeida. “Sobre Arquivos Pessoais". Arquivo \& Administração, Rio de Janeiro, v. 7, n. 2, PP. 5-9, jul-dez, 2008.

HEYMANN, Luciana Quillet. O arquivo utópico de Darcy Ribeiro. História, Ciências, saúde-Manguinhos, Rio de Janeiro, v. 19, n.1, jan.-mar. 2012, p.261-282.

HEYMANN, Luciana Quillet. O indivíduo fora do lugar. Revista do Arquivo Público Mineiro, Belo Horizonte, n.2 pp.40-57, jul-dez, 2009, p. 48.

NEDEL, Letícia Borges. 'Da Sala de Jantar à Sala de Consultas: o arquivo pessoal de Getúlio Vargas nos embates da história política recentes. In: TRAVANCAS, Isabel; ROUCHOU, Joelle; HEYMANN, Luciana. (Org.). Arquivos Pessoais: reflexões multidisciplinares e experiências de pesquisa. $1 \mathrm{ed.}$ Rio de Janeiro: Editora

FGV/FAPERJ, 2014, v. 1, p. 131-164, p.7.

MCNEIL, Legs \& MCGAIN, Giullian. Mate-me por favor: Uma história sem censura do punk. Porto Alegre - L\&PM, 1997.

VINCI DE MORAES, José Geraldo. Música en conserva. In: Memoria e Historia de la música en Brasil. VINCI DE MORAES, José Geraldo,MACHADO, Cacá. en BRESCIANO, Juan. La memoria histórica y sus configuraciones temáticas. Una aproximación interdisciplinaria. Montevideo, Ediciones Cruz del Sur, 2011. 